\title{
Contribuição da Ciência da Terra para a formação científica na Educação Básica: produção de materiais didáticos e práticas de Ciências Naturais
}

\author{
Carlos Roberto dos Anjos Candeiro ${ }^{1}$ \\ Suely Aparecida Gomes Moreira ${ }^{2}$ \\ Tamires do Carmo Dias ${ }^{3}$
}

\begin{abstract}
RESUMO
Neste artigo, aborda-se uma experiência teórico/prática a partir da produção de materiais didáticos para subsidiar o processo ensinoaprendizagem na educação básica, de conteúdos relativos às Ciências Naturais. Apresentar-se-á conceitos básicos de Geociências relacionados à construção e uso de caixa de minerais e rochas pelos discentes de graduação, na disciplina de Geologia.
\end{abstract}

PALAVRAS-CHAVE: Material didático. Ciências da Terra. Formação Científica. Ensino Básico.

Contribution of Earth Science to scientific education in Basic Education: production of teaching materials and practices in Natural Sciences

\begin{abstract}
In this article, we approach a theoretical/practical experience based on the production of didactic materials to support the teaching-learning process in basic education, with content related to Natural Sciences. Basic concepts of Geosciences related to the construction and use of mineral and
\end{abstract}

\footnotetext{
${ }^{1}$ Doutor em Geologia. Universidade Federal de Goiás, Goiânia, Goiás, Brasil. https://orcid.org/0000-0002-8128-4660. candeiro@ufg.br.

${ }^{2}$ Doutora em Geografia. Universidade Federal de Uberlândia, Uberlândia, Minas Gerais, Brasil. https://orcid.org/00000002-9913-0782. suelygomesgeo@gmail.com.

${ }^{3}$ Licenciada em Ciências Biológicas.Universidade Federal de Goiás, Goiânia, GO, Brasil. https://orcid.org/0000-00023828-6337.dias.tamiresdc@gmail.com.
} 
rock boxes by undergraduate students in the discipline of Geology will be presented.

KEYWORDS: Courseware. Earth Sciences. Scientific Formation. Basic education.

Contribución de las ciencias de la tierra a la educación científica en la Educación Básica: producción de materiales y prácticas docentes en Ciencias Naturales

\section{RESUMEN}

En este artículo se aborda una experiencia teórico-práctica a partir de la producción de materiales didácticos para apoyar el proceso de enseñanzaaprendizaje en la educación basica, con contenidos relacionados con las Ciencias Naturales. Se presentarán conceptos básicos de Geociencias relacionados con la construcción y uso de cajas de minerales y rocas por estudiantes de pregrado en la disciplina de Geología.

PALABRAS CLAVE: Material didáctico. Ciencias de la tierra. Formación científica Educacion Basica.

$$
* * *
$$

\section{Introdução}

A partir do princípio de que a educação escolar deve promover uma formação cidadã, o processo de ensino-aprendizagem torna-se uma das principais preocupações em nossa sociedade, suscitando inúmeras reflexões e ações pelos seus atores (professores, estudantes e pesquisadores). Diante das necessidades educativas contemporâneas é indispensável (re)pensar, dentre outros fatores, as metodologias de ensino-aprendizagem que possam estimular os discentes a desenvolverem a capacidade de raciocínio, julgamento e criticidade, que facilitem a compreensão da organização espacial como produto das relações sociais, isto é, que entendam as dinâmicas da 
natureza a partir das mediações do trabalho humano, da evolução tecnológica e dos fenômenos naturais.

Nesse sentido, as reflexões e ações na área das Ciências Humanas, por exemplo, na Pedagogia, na Geografia, nas Artes e na História, dentre outras áreas, têm ocorrido de forma bastante enfática e incisiva. Atualmente as preocupações no campo da "Didática", tradicionalmente pesquisada sob a denominação de "ensino", vêm se fortalecendo, haja vista os investimentos significativos em programas de formação inicial e continuada de professores, na realização de eventos acadêmicos e em publicações científicas. No Brasil, novos grupos de pesquisadores têm buscado discutir e propor metodologias alternativas para que o processo ensino-aprendizagem contribua com a formação de estudantes mais críticos e atuantes propositivamente na sociedade em que vivem.

Por outro lado, as interações, reflexões e intervenções no campo das denominadas Ciências Naturais ainda são incipientes. As Ciências Biológicas (sensu Biologia) e a Química são as áreas do conhecimento das Ciências Naturais que mais têm compartilhado experiências e vivências acerca do binômio ensino-aprendizagem. Ainda é pouco conhecido nos meios acadêmicos e, principalmente, na educação básica, as experiências e pesquisas da área de Geociências (sensu Geologia).

A partir do exposto, esse artigo relata uma experiência de produção de material didático de Geologia, cujo objetivo foi subsidiar professores das áreas de Ciências Naturais e da Terra, que atuam em escolas de ensino fundamental da rede pública do município de Ituiutaba-MG. Inicialmente, o texto apresenta brevemente os temas relacionados à Geologia estudados na educação básica. Em seguida, descreve um relato da experiência de produção de um material alternativo, denominado "Caixa Didática de Geologia", construída por estudantes de graduação em Geografia. Por fim, ressalta a importância da produção de materiais didáticos alternativos para o ensino de Geologia considerando, dentre outros aspectos, os desafios cotidianos que se dispõem ao ensino dessa área do conhecimento no ambiente escolar. 
O presente artigo será organizado a partir da apresentação dos conhecimentos básicos teóricos sobre a Geologia, desenvolvimento, conclusão e referencial utilizado. Desta forma possibilitamos que o leitor interessado possa construir o material didático de apoio para aulas de Geociências.

\section{Estudo de Geologia na Educação Básica}

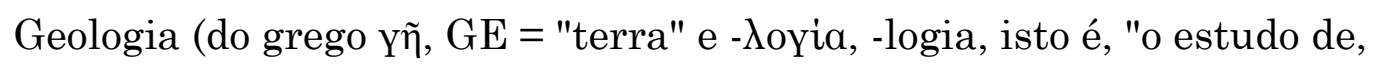
discurso" CPRM, 2016) é a ciência que compreende o estudo da Terra, das rochas e sua composição, e os processos relacionados às mesmas. A Geologia pode, também, referir-se geralmente ao estudo dos recursos sólidos de qualquer corpo celeste (como a geologia da Lua ou de Marte, por exemplo). Essa ciência permite uma visão sobre a história geológica da Terra favorecida, principalmente, pelas evidências da Tectônica de Placas, da história evolutiva da vida e dos climas existentes no passado do nosso Planeta. Nos tempos atuais, a Geologia é comercialmente valorizada, pois seus estudos relacionamse com a extração de minérios (mineral ou rocha de importância comercial), e com a exploração de hidrocarbonetos (petróleo), bem como a exploração e pesquisas sobre os recursos hídricos. Essa Ciência da Terra é muito importante para a previsão e compreensão dos riscos naturais, a mitigação de problemas ambientais relacionados à crosta da Terra, além de desempenhar um papel saliente na engenharia geotécnica. Tal relevância tem garantido a presença da Geologia no currículo escolar, a partir do estudo de temas a ela relacionados, desde a educação básica (Ensino Fundamental e Médio) até alguns cursos superiores, como Geografia e Biologia, dentre outros.

Os Parâmetros Curriculares Nacionais-PCNs (BRASIL, 1998), recomendam o ensino das Ciências Naturais como um tema transversal para ensino fundamental ( $1^{\circ}$ ao $9^{\circ}$ ano). Os PCNs (1998) orientam que esse ensino deve colaborar para a compreensão do mundo, situando o homem como indivíduo participativo e parte integrante do Universo. Defende, ainda, que a apropriação de conhecimentos desta área contribui para a ampliação das 
explicações acerca dos fenômenos naturais, para a compreensão, valorização e transformação dos modos de intervir na natureza e de utilizar seus recursos. Assim, os conteúdos de Geologia são estudados principalmente no ensino fundamental, dentro da proposta curricular de Geografia, e em menor proporção nas áreas de Biologia, Química, Física e Ciências.

Nesse sentido, os temas da Geologia são ensinados durante todo o processo de escolarização, envolvem conteúdos que perpassam outras ciências, suscitando enfoques diversificados. Os principais conteúdos programáticos de Geologia abordados em Geografia na educação básica são:

QUADRO 1: Conteúdos programáticos abordados na Educação Básica

\begin{tabular}{|l|l|}
\hline & A Terra e o Universo \\
& - Via Láctea. \\
& - A Terra e o Sistema Solar. \\
$\mathbf{6}^{\mathbf{0}}$ ano & - A idade da Terra. \\
& - Os fósseis na natureza. \\
& - A reconstituição de antigos ambientes terrestres - as paleopaisagens. \\
\hline $\mathbf{7}^{\mathbf{0}}$ ano & - \\
\hline $\mathbf{8}^{\mathbf{0}}$ ano & $\begin{array}{l}\text { A natureza, seus fenômenos e a transformação do espaço natural } \\
- \text { A formação e a transformação da Terra. }\end{array}$ \\
\hline $\mathbf{9}^{\mathbf{0}}$ ano & $\begin{array}{l}\text { - A dinâmica da natureza - interdependência entre clima, relevo, vegetação } \\
\text { e solo. }\end{array}$ \\
\hline
\end{tabular}

Fonte: Elaborado pelos autores.

A abordagem desses conteúdos deve estar ancorados na perspectiva do ensino baseado na construção de conceitos pelos estudantes, tendo o professor como mediador. Atualmente, essa tem sido uma exigência e, sem dúvidas, um grande desafio para docentes que atuam na educação básica. Todos os conceitos, quando abordados, devem ser resultado de um processo criativo e 
orientado para a contextualização e resolução de problemas, evitando o exercício de memorização, que não contribua para formação do aluno (CAVALCANTI, 1998).

Segundo Garcia (1997), a situação de encontro do professor com os seus alunos é um momento importante e decisivo, uma dimensão de tempo e espaço possível para se viver a possibilidade de aprendizagem que apresente aos estudantes um mundo para ser visto, pensado, debatido e revisado. Ainda para esta autora, é uma possibilidade de conhecer e aprender mutuamente, de maneira colaborativa. Os conhecimentos de Geologia permitem amplas possibilidades de exercitar o ensino e a aprendizagem significativa, uma vez que pode se trabalhar com o mundo real, muito mais próximo ao cotidiano dos sujeitos envolvidos nesse processo (discentes e docentes).

O espaço da sala de aula é um lugar privilegiado para que a aprendizagem de conteúdos de Geologia se desenvolva, assim como o ambiente externo à sala, que pode ser a própria escola, a casa, o bairro e outras áreas urbanas ou rurais. Compiani e Carneiro (1993) ressaltam que não é possível abordar todos os conjuntos de elementos que formam o objeto de investigação da Geologia com um enfoque exclusivamente teórico e que a interação com a realidade empírica oferece infinitamente inúmeras oportunidades e possibilidades de aprendizagem.

Os conteúdos/conceitos de Geologia para o Ensino Fundamental podem ser inseridos na análise denominada de "Aprendizagem Significativa" de Ausubel (2003). Nessa abordagem, a aprendizagem corresponde a um processo no qual um novo dado se relaciona com um aspecto relevante da estrutura do conhecimento do indivíduo, possibilitando o estabelecimento de relações com experiências concretas deste com outras áreas do conhecimento, ou seja, aos novos conteúdos internalizados.

Experiências bem sucedidas que consideram a perspectiva da "Aprendizagem Significativa" na área da Geologia têm sido narradas em diversos trabalhos (LOPES, CARNEIRO, 2009). 


\section{Materiais e métodos}

O desenvolvimento de um recurso didático relacionado à temática "Minerais e Rochas" para ensino-aprendizagem de conteúdos de Geologia compreende a elaboração de caixas de espécimes geológicos. A produção desse material tem como objetivo auxiliar os professores da educação básica no processo ensino-aprendizagem, especialmente os estudantes do $6^{\circ}$ ano do ensino fundamental. A produção deste kit didático denominado "Caixa de Minerais e Rochas" foi realizada pelos discentes da disciplina Geologia, ministrada no Curso de Geografia da Faculdade de Ciências Integradas do Pontal, Campus Pontal-Ituiutaba da Universidade Federal de Uberlândia. Seguindo as orientações e mediações do professor da referida disciplina, os estudantes podem confeccioná-la individualmente ou em dupla.

O roteiro básico para a construção da caixa e a classificação dos espécimes de minerais e rochas foi estudado, a partir das seguintes orientações:

- Número de discente por caixa: No máximo dois.

- Cada caixa deverá conter:

a. Três minerais (obrigatório um exemplar de quartzo);

b. Duas rochas ígneas (granito e basalto);

c. Três rochas metamórficas (obrigatório um exemplar de mármore);

d. Três rochas sedimentares (obrigatório um exemplar de arenito);

e. Todos os espécimes devem estar limpos e devidamente acondicionados em pequenos sacos plásticos transparentes;

f. Um frasco com ácido acético (vinagre), com a identificação do seu conteúdo;

g. Um pedaço de cerâmica branca e uma flanela de cor laranja; 
h. Caixa envernizada tamanho padrão identificada com uma ficha informativa (ver abaixo) afixada com plástico contact em sua sua tampa.

i. Um pedaço de ímã.

j. Uma lupa.

Depois de concluída a construção da "Caixa de Minerais e Rochas" (Figura 1), os kits didáticos foram doados às Escolas do Ensino Fundamental e Médio do município de Ituiutaba-MG (no ano de 2011 foram doadas três "Caixa de Minerais e Rochas" à Escola de Educação Básica-Eseba da Universidade Federal de Uberlândia-MG). A cada ano são escolhidas três escolas da rede ensino de Ituiutaba-MG, das quais são convidados os professores de Geografia do Ensino Fundamental para participarem de uma oficina pedagógica. Esse momento destina-se à abordagem dos conteúdos básicos de Geologia relacionados à classificação e uso de minerais e rochas, destacando a forma mais adequada de abordar os conteúdos das caixas com os estudantes em sala de aula (ou no laboratório didático, caso exista na escola). Na oportunidade, são doadas doze "Caixa de Minerais e Rochas", em média, para cada escola, o que possibilita o trabalho com grupos de três ou quatro alunos para cada kit didático. 
FIGURA 1: Caixa didática de Minerais e Rochas produzidas nas disciplina de Geologia, Curso de Geografia do Campus Pontal-UFU.

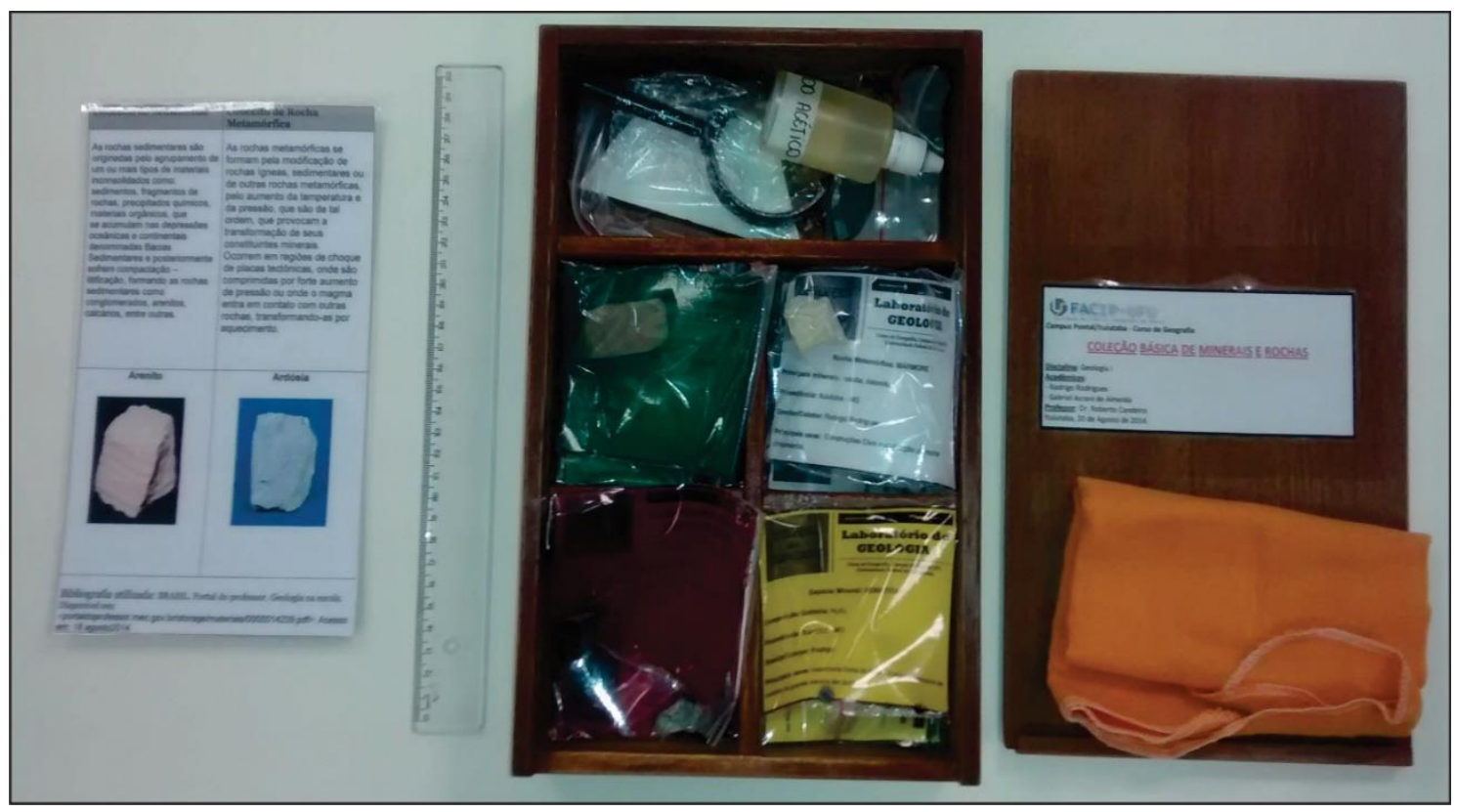

Fonte: Arquivo dos autores.

Uma característica central que define o uso dessa "Caixa de Minerais e Rochas" é o fato de ser exemplares com materiais utilizados no cotidiano. Os espécimes geológicos possibilitam que a Geologia possa ser compreendida a partir do seu uso cotidiano (por exemplo, em construções e na indústria), em conformidade com o que Ausubel (2003) denomina de "Aprendizagem Significativa”. O trabalho com estes kits constitui procedimento metodológico importante para as Geociências (CARNEIRO, 1997), na medida em que permite trabalhar conteúdos específicos facilitando o processo ensinoaprendizagem em diferentes níveis de ensino.

\section{A caixa de Minerais e Rochas e os conteúdos de Geologia}

O desenvolvimento e a utilização das Caixas de Minerais e Rochas basearam-se em extensiva consulta bibliográfica. Na etapa de definição do público-alvo - alunos do $6^{\circ}$ ano do Ensino Fundamental, definiram-se a diretriz pedagógica e os conteúdos presentes nesse ano de ensino. A principal 
referência para elaboração da caixa de Minerais e Rochas foram as experiências de Cunha et al. (2008), e Candeiro et al. (2009), que apresentam diferentes maneiras de se trabalhar conteúdos aplicados ao ensino e espécimes geológicos. Estes autores relatam que atividades didáticas originadas nos cursos de graduação de Geografia e Química podem ser aplicadas, possibilitando assim atender às Diretrizes Curriculares Nacionais para formação dos graduandos de Geologia e Geografia. Essa atividade buscou articular teoria e prática durante a graduação por meio da interpretação de conteúdos básicos de minerais e rochas. A caixa possui características relacionáveis a quatro categorias clássicas conhecidas dos espécimes geológicos: minerais, rochas ígneas, rochas sedimentares e rochas metamórficas.

Para que a mediação pedagógica nas escolas de educação básica aconteça de maneira propositiva, a partir do uso das Caixas de Minerais e Rochas, é necessário que os docentes tenham vivenciado situações de ensinoaprendizagem teórico-práticas que lhes possibilitem a compreensão de conceitos básicos sobre os espécimes geológicos. Além disso, docentes devem saber relacionar esses conhecimentos adquiridos durante a sua formação inicial e continuada, com aqueles saberes prévios trazidos pelos estudantes sobre o ciclo das rochas na natureza. A partir desses conhecimentos básicos é possível orientar os alunos para trabalharem adequadamente com as Caixas de Minerais e Rochas e, com o auxílio desse recurso didático, construírem novos conhecimentos que lhes sejam significativos para melhor se relacionarem com a natureza.

Para o desenvolvimento das atividades o docente deve orientar os estudantes a formarem pequenos grupos, para que cada equipe possa trabalhar cooperativamente na análise dos espécimes geológicos. Os alunos devem ser orientados a consultar a ficha de conceitos, que é parte integrante da caixa, e confrontar cada conceito com o espécime em mãos. Essa tentativa de identificar os minerais e rochas é uma tarefa que pode ser difícil para os estudantes da educação básica, mas à medida que forem adquirindo 
experiência a tarefa vai se tornando cada vez mais fácil. Com o uso da Caixa de Minerais e Rochas é possível realizar a identificação destes espécimes sem o uso de equipamento ou análises sofisticadas, procedimentos mais complexos comumente utilizados em práticas de laboratório de identificação concretizadas somente nos cursos de Ensino Superior. Para o trabalho em sala de aula do ensino fundamental, sugere-se ao professor que apresente um roteiro para orientar os alunos na análise de cada espécime, realizando os testes na própria sala de aula.

Para realizar a identificação de espécimes geológicos pelo exame a olho $\mathrm{nu}$, verificam-se as propriedades físicas dos minerais e rochas. Os livros de Geologia geralmente apresentam os minerais e as rochas classificados pela composição química, iniciando com os elementos nativos (ouro, prata, diamante, enxofre, etc.), que são quimicamente mais simples. Posteriormente, observam-se os de composição mais complexa (sulfetos, cloretos, sulfatos, carbonatos, silicatos e assim por diante), ou mesmo por diferentes categorias de rochas (ex. ácidas, básicas). Essa forma de explanação é coerente, mas não muito eficaz quando se estuda Ciências Naturais no ensino fundamental.

Para o trabalho com a categoria Mineral, em sala de aula, é importante mencionar que os materiais disponíveis na Caixa de Minerais e Rochas são simples e de baixo custo: um pedaço de cerâmica branca; ímã (pequeno); lupa de pequeno aumento; frasco com ácido acético (vinagre).

As propriedades físicas dos minerais (adaptado CPRM, 2014): são muitas as propriedades físicas usadas na identificação de minerais e, de certa forma, de rochas. Para algumas espécies, uma identidade é a cor (ex.: ouro, prata); alguns têm como características diagnósticas o magnetismo (ex.: magnetita, basalto com boa concentração de ferro) ou a clivagem para os minerais como a calcita, as micas, por exemplo. Com um pouco de prática aprende-se a observar a propriedade que cada espécie tem de mais característico.

Cor - alguns minerais têm cor variável (minerais alocromáticos), mas outros têm sempre a mesma cor (minerais idiocromáticos) e isso auxilia na 
sua identificação. A pirita sempre apresenta uma coloração amarela e a malaquita apresenta sempre uma coloração verde. $\mathrm{O}$ quartzo pode ser incolor (cristal-de-rocha), amarelo, laranja, vermelho (citrino), preto (mórion), roxo (ametista), rosa, cinza, branco, dentre outras. A cor do espécime deve ser observada numa superfície fresca, como a de uma fratura recente. A cor de alguns minerais altera-se facilmente. Quebrando o mineral, observa-se a cor verdadeira.

Para se realizar o teste de dureza, os alunos devem escolher uma superfície do mineral ou rocha a ser testada que não esteja alterada/suja (superfície fresca). Não é necessário um risco grande, apenas dois ou três milímetros são suficientes. Após friccionar um material de dureza conhecida contra o mineral, removem-se partículas que ficaram soltas para observar se este realmente foi riscado. As partículas podem não ser do mineral que está sendo testado, mas do mineral de dureza já conhecida.

Magnetismo - alguns minerais são atraídos por um ímã de mão, o que ajuda na sua identificação. Dois exemplos são a magnetita (daí a origem da palavra magnetismo) e a pirrotita. Para melhor observar se o mineral é magnético, deve-se amarrar o ímã em um fio fino e flexível e aproximá-lo do mineral.

Reação ao ácido clorídrico - Há substâncias que sob a ação de uma gota de ácido acético a frio ocorre uma efervescência, liberando dióxido de carbono. Exemplos disso são a calcita, calcários e mármores. Como o carbonato de cálcio é um composto químico muito comum, vale a pena realizar sempre este teste.

Foi possível verificar as possibilidades da ampliação do uso da Caixa Didática de Minerais e Rochas como recurso didático propositivo nos processos de ensino-aprendizagem de Geologia. Paralelamente ao trabalho em sala de aula com alunos do $6^{\circ}$ ano do Ensino Fundamental, esse recurso didático serve como instrumento de apoio ao professor na construção/compreensão dos conceitos de Minerais e Rochas. Além destes, outros aspectos ainda podem ser analisados, como o nível de motivação dos 
alunos, identificação e busca de solução de problemas de maneira intuitiva, troca de experiências e socialização de conhecimentos de Geologia, interação professor-aluno e aluno-aluno. Deve-se acrescentar, ainda, a análise do desenvolvimento do raciocínio dos alunos sob o ponto de vista lógico e a profundidade de utilização desses conceitos geológicos.

A aplicação das Caixas de Minerais e Rochas tem se mostrado adequada à utilização em sala de aula como apoio às atividades descritas nas orientações didáticas (livros, apostilas, dentre outros) utilizadas pelo professor. A estrutura de composição e utilização desses kits se mostra adequadas à utilização em sala de aula ou laboratório didático. O nível de motivação e interação dos alunos revela que este recurso didático pode promover um aumento efetivo de interesse do participante com relação a termos e conceitos específicos da Geologia no ensino fundamental. Pode-se apontar que a utilização das Caixas de Minerais e Rochas possibilita aproximar ainda mais os alunos em direção a um trabalho colaborativo, pois permite a interação entre os pares e entre os grupos, possibilitando troca de experiências e construção de novos conhecimentos acerca dos conceitos/conteúdos da Geologia.

\section{Conclusão}

Os poucos trabalhos que abordam a utilização de espécimes geológicos no processo ensino-aprendizagem no ensino fundamental exigiu, no presente estudo, um esforço para elaborar a fundamentação teórica da pesquisa e construir o kit didático denominado Caixa de Minerais e Rochas. Esse kit pode ainda demandar aprimoramentos subsequentes, especialmente no que tange aos seus conteúdos teóricos (fichas) e de espécimes, além de uma avaliação de sua eficiência no processo ensino-aprendizagem. Todavia, acreditamos que a proposta apresentada permite adaptações de acordo com a realidade de cada público escolar e, em linhas gerais, facilita a compreensão, por parte dos estudantes do ensino fundamental, dos conceitos e espécimes relacionados ao 
ensino de Geologia. As Caixas de Minerais e Rochas podem proporcionar a construção de conhecimento em diferentes faixas etárias e públicos-alvo nos distintos anos do ensino fundamental e/ou médio.

A abordagem de temas de Geologia no Ensino Fundamental, em especial, necessita de metodologias alternativas, que possibilitem uma construção ativa de conhecimentos. A utilização de kits didáticos como esse aqui proposto constitui-se numa alternativa para o aprendizado da Geologia. As ações de produção de materiais didáticos alternativos contribuem para a utilização propositiva de espécimes geológicos, e ampliam as práticas didático-pedagógicas na graduação, nas suas atividades de ensino, pesquisa e extensão. Ancoradas em reflexões teóricas e em experiências práticas, na condição de participantes, de organizadores e de coordenadores dessas atividades foi possível observar que a experiencia diática contribuiu de modo significativo com a melhoria da formação continuada dos professores, dos estudantes e, mais amplamente, com a melhoria da educação em nosso país.

Conjuntamente, a atuação dos licenciandos em projetos como esse aqui exposto contribui com sua formação como futuro professor, propiciando o contato com materiais didático-pedagógicos diferenciados, e com as interações entre os sujeitos escolares e a produção de conhecimento por meio de atividades práticas de ensino de Geologia no cotidiano de escolas públicas de educação básica. Assim, a participação de alunos de graduação pode contribuir para o desenvolvimento de atividades que permitam o seu contato com diferentes realidades sociais, promovendo a integração da formação acadêmica com sua futura atividade profissional.

A participação efetiva dos estudantes e dos professores em situações reais de ensino-aprendizagem proporciona o desenvolvimento de habilidades próprias do processo de produção do conhecimento. Isso amplia a oportunidade de os discentes vivenciarem questões relacionadas ao seu cotidiano e de desenvolverem habilidades de análise e solução de problemas. Espera-se que o estudo aqui apresentado contribua para socializar e 
estimular outras iniciativas e trabalhos nessa linha de pesquisa, ainda pouco enfatizada no âmbito da Geografia e ciências afins no ensino fundamental.

\section{Referências}

AUSUBEL, D. P. (Ed.). Aquisição e retenção de conhecimentos: uma perspectiva cognitiva. Lisboa: Plátano Edições Técnicas, 2003.

BERGQVIST, L.P.; PRESTES, S.B.S. Kit paleontológico: um material didático com abordagem investigativa. Ciência \& Educação, Campinas, v. 20, n. 3, p. 345-357, jun. 2014.

BRASIL. Ministério da Educação. Parâmetros Curriculares Nacionais. Geografia (5ª $8^{\circ}$ série), SEF, Brasília, 1998.

BRASIL. Parâmetros Curriculares Nacionais Ensino Médio. 1998c. Orientações Educacionais Complementares aos Parâmetros Curriculares Nacionais: Ciências da Natureza, Matemática e suas Tecnologias. Brasília, DF, MEC/Secretaria de Educação Fundamental. Disponível em:

$<$ http://portal.mec.gov.br/seb/index.php?option=content\&task=view\&id=408\&Itemi d=394> Acesso em 27/03/2007.

BRASIL. Parâmetros Curriculares Nacionais. 1998d. Terceiro e quarto ciclos do ensino fundamental - Ciências Naturais. Brasília, DF, MEC/Secretaria de Educação Fundamental, 138p. Disponível em: <http://portal.mec.

gov.br/seb/index.php?option=content\&task=view\&id=264\&Itemid=254> Acesso em 27/03/2007.

CANDEIRO, C.R.A.; MOURA, G.G.; NUNES, S.I.; AMANCIO-PEREIRA, F. El Trato com el Conocimiento em la Asignatura Geología General en el Curso de Geografía del Campus do Pontal de la Universidade Federal de Uberlância (MG): un relato de experiencias. In: II SIMPÓSIO DE PESQUISA EM ENSINO E HISTÓRIA DE CIÊNCIAS DA TERRA IV SIMPÓSIO NACIONAL O ENSINO DE GEOLOGIA NO BRASIL, II, 2009, São Paulo. Anais... 2009, v. 1. p. 190-197.

CPRM—Serviço Geológico do Brasil. 2016. Disponível em http://www.cprm.gov.br/publique/cgi/cgilua.exe/sys/start.htm?infoid=1042\&sid=129

CAVALCANTI, L. S. (Ed.). Geografia, Escola e Construção de Conhecimentos. Campinas, SP: Editora Papirus, 1998.

COMPIANI, M.; CARNEIRO, C.R. Os papeis didáticos das excursões geológicas. Enseñanza de las Ciencias de la Tierra, Madri, v. 1, n.2, p. 90-98, abr. 1993.

CUNHA, C. J.; GUIMARÃES, O. M.; Araújo, M. P.; VASCONCELlOS, E. M. G. ; MARTINS, J. M. ; NETO, J. M. DOS R. ; MARTINS, F. M. Ensino de técnicas de análises de minerais com ênfase na interpretação de dados: articulando teoria e 
prática na formação do geólogo. Terrae. Série didática, Campinas, v. 4, p. 1-10, jan. 2008.

LOPES, O. R.; CARNEIRO, C. R.. O jogo "Ciclo das Rochas" para ensino de Geociências. Revista Brasileira de Geociências, São Paulo, v. 39, p. 30-41, jan. 2009.

Recebido em janeiro de 2020.

Aprovado em junho de 2020. 